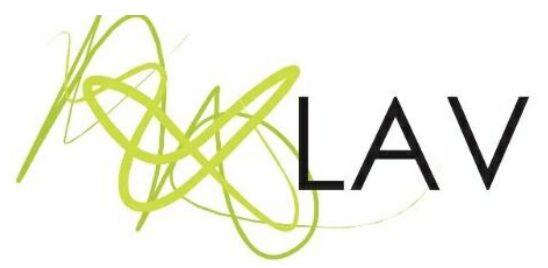

\title{
O governo e o autogoverno do aluno no ensino do desenho em Portugal (séculos 18 e 19)
}

Student government and self-government in drawing teaching in Portugal (18 ${ }^{\text {th }}$ and $19^{\text {th }}$ centuries)

Catarina Silva Martins ${ }^{i}$ Faculdade de Belas-Artes da Universidade do Porto

\begin{abstract}
Resumo
O texto aborda a emergência de um pensamento sobre a educação artística das crianças e jovens portugueses, a partir de uma perspectiva de governamentalidade. Duas linhas genealógicas sobressaem no tempo histórico aqui delineado, que vai do final do século 18 ao final do século 19. Por um lado, o propósito governativo das artes era o de fabricar o cidadão da nação como trabalhador, explorando os potenciais subjetivadores das artes, particularmente em termos do autogoverno do aluno; por outro lado, os capitais simbólicos e culturais a elas associados funcionavam também como terrenos de distinção na fabricação de tipos de pessoa.
\end{abstract}

Palavras-chave: desenho, governamentalidade, modernidade pedagógica, educação artística, Portugal.

\begin{abstract}
The text addresses the emergence of a thought about the artistic education of Portuguese children and young people, from a governmentality perspective. Two genealogical lines stand out in the historical time outlined here, which goes from the late eighteenth century to the late nineteenth century. On the one hand, the governing purpose of the arts was to mold the citizen of the nation as worker, exploiting the potential of subjectivation of the arts, particularly in terms of student self-government; on the other hand, the symbolic and cultural capitals associated with arts also made it an area of distinction in molding kinds of people.
\end{abstract}

Keywords: drawing, governmentality, pedagogical modernity, arts education, Portugal.

Enviado em: 12/03/21 - Aprovado em: 08/05/21

Foi em uma dinâmica de moralização das populações, particularmente dirigida para franjas populacionais de crianças e jovens 'em risco', que a educação artística começou por ser concebida em Portugal, em finais do século 18, e se viu inserida no sistema público

Revista Digital do LAV - Santa Maria - vol. 14, n. 2, p. 359 - 384 - mai./ago. 2021 ISSN 1983 - 7348 http://dx.doi.org/10.5902/1983734864729 
de ensino, já no século 19. Que as artes tenham sido vistas como uma área privilegiada para a tutela de menores em risco, como hoje os designaríamos, corresponde a um entendimento de que elas seriam uma tecnologia capaz de transformar, a partir de dentro, aqueles que as praticassem, pela ativação de princípios de cuidado de si, que Michel Foucault designou como parte das "tecnologias do eu" (FOUCAULT, 1988). Não é, pois, de se estranhar que o palco privilegiado para o ensaio de uma modernidade pedagógica no ensino das artes em Portugal tenha sido a Casa Pia de Lisboa. Criada em 1780 e destinada a acolher e educar crianças a partir de separações internas pelo gênero, pelo tipo de delinquência, idade, aptidão, etc, estabeleceu-se, nas palavras de Jorge Ramos do Ó (2003), como um "laboratório da modernidade educativa portuguesa". De facto, foi ali que as mais diversas cambiantes sociais e de comportamento começaram a encontrar matizes diversas, capazes de separar e, simultaneamente, de tornar o 'Outro', que era a criança 'problema', em objeto de governo. Dirigidas a grupos de crianças e jovens órfãos, indigentes e anormais, as artes foram pensadas e estruturadas como componente central da educação e os programas ali ensaiados viriam a incorporar, já nas últimas décadas do século 19, os discursos pedagógicos em Portugal.

Contudo, as artes em Portugal tiveram um começo paralelo ao da Casa Pia de Lisboa, em outra instituição, sendo esta dedicada a uma população nobre, o Real Colégio dos Nobres. Essas duas linhas genealógicas, que podemos hoje encontrar ainda tão presentes num pensamento sobre a educação artística e as suas missões, estabeleceramse a par, sem nunca mais se afastarem. Por um lado, as artes como uma forma de governar o 'eu' das crianças e dos jovens, por múltiplas tecnologias disciplinares e do 'eu'; por outro lado, as artes como formas de capital simbólico e cultural, capazes de distinguir num plano social, econômico e educativo, diferentes tipos de ser sujeito (BOURDIEU, 2007). Numa e noutra, as artes na educação foram pensadas a partir da racionalidade que então se colocava na Europa Ocidental, por via de uma lógica colonial e imperialista, da civilização contra a barbárie, da ordem contra a desordem, do racional contra o que era considerado irracional e, mesmo dentro de fronteiras, esse 'Outro', o aluno da Casa Pia, era aquele que, representando o perigo do ingovernável, justificava todas as ações tidas para a sua 'regeneração'. Por outro lado, o eu do sujeito nobre delineava-se a partir dessas práticas de subjetivação e de distinção em relação a esses lugares considerados como 'ainda-não' (CHAKRABARTY, 2008).

Nesse sentido, as artes na educação ${ }^{1}$ como em outros domínios, a exemplo dos museus, serviram a um propósito salvacionista, tendo as diversas retóricas que aí se

\footnotetext{
${ }^{1}$ Vale dizer que, historicamente, as artes na educação foram pensadas para um sujeito masculino, sendo, na educação feminina, remetidas para atividades manuais como bordar ou coser, ou, na educação nobre, como uma
}

Revista Digital do LAV - Santa Maria - vol. 14, n. 2, p. 359 - 384 - mai./ago. 2021 ISSN 1983 - 7348 http://dx.doi.org/10.5902/1983734864729 
iniciaram, da sua instrumentalização e dos seus efeitos (GAZTAMBIDE-FÉRNANDEZ, 2013; MARTINS, 2018), chegado aos dias de hoje. Essas retóricas e esses efeitos cumpriam propósitos governamentais. É importante introduzir aqui o conceito Foucaultiano (FOUCAULT, 1991) de governamentalidade como forma de condução da conduta. Entendida sob o prisma da governamentalidade, a educação artística emerge como um campo de produção de saber e de poder; saber sobre a interioridade dos alunos, alimentando estratégias de poder cada vez mais dirigidas à alma e aos comportamentos, e cada vez menos centradas em ações de força.

Neste artigo, começaremos por focalizar essas duas instituições para logo abrir uma arena maior na qual o desenho se constituiu como objeto de atenção pedagógica e governamental. Foi, sobretudo ao nível das artes visuais, que a educação artística foi pensada para as massas, sendo o desenho a área que mais investimento discursivo revelou, assumindo-se como o sublime tecnológico da nação. Procuraremos traçar uma imagem das artes na educação nos finais do século 18 e durante o século 19, centrando a discussão nos argumentos e descrições que então emergiram na questão da formação de um cidadão moderno, sujeito dócil e útil, capaz de se adaptar e responder ao mundo do trabalho e de se alinhar por princípios culturais associados a um maior desenvolvimento e progresso.

Se, na arena educativa, o princípio da igualdade começava a estabelecer-se como aquele que seria comum a todos as crianças, respondendo aos anseios de uma burguesia que lutava contra os lugares sociais impostos pelo nascimento nobre, conceitos como aptidão, talento e mérito viam-se construídos como os elementos a partir dos quais todos os sujeitos seriam, de ora em diante, medidos, distinguidos e, por meio disso, os gestos de exclusão se justificam, com base numa ideia linear de desenvolvimento. A aptidão surgiria então como o instrumento capaz de dividir a sociedade a partir daquele que seria o próprio destino profissional de cada um, e a ideia de desenvolvimento distinguiria as crianças normais e as anormais dentro da categoria da infância.

Estabeleceu-se, pois, uma distribuição policial sensível que apareceu expressa em Almeida Garrett (1829) no seu tratado Da Educação. O ensino artístico justificava-se na dependência da origem social e do futuro profissional imaginado para o educando:

Mas a quem não faz profissão das artes, convém-lhe, no estado actual dos conhecimentos humanos, descer do estudo das ciências para o das artes. As artes são mecânicas propriamente ditas ou

'prenda' que permitira à mulher, num plano simbólico e de entretenimento, ocupar um lugar social construído tendo por base uma série de características consideradas femininas. Neste artigo, focaremos nesse discurso mais generalista sobre as artes como uma tecnologia de governo na fabricação do cidadão moderno, apontando que este era um discurso excludente.

Revista Digital do LAV - Santa Maria - vol. 14, n. 2, p. 359 - 384 - mai./ago. 2021 ISSN 1983 - 7348 http://dx.doi.org/10.5902/1983734864729 
liberais e ditas belas artes. Das primeiras pouco tem que aprender o pupilo nobre; das segundas, todas devem estudar mais ou menos, e algumas praticar. A música, o desenho (incluindo neste a pintura) e a dança, pode-se dizer que fica mal a uma pessoa de bem não as saber, e até certo ponto, não as praticar. Naturalmente, porém nos chama a inclinação mais para uma ou outra destas prendas; e nisso a indulgência do educador deve ceder fácil à vontade do pupilo, e deixar-lhe dar preferência àquela que mais o atrair, contanto que não despreze as outras (GARRETT, 1829, p. 44-46).

Falar das artes como destino profissional colocava em jogo diferentes estatutos, dependendo de se tratava da formação de uma elite ou de uma classe operária.

\section{As artes no ensino dos nobres}

Por carta de lei de 7 de março de 1761, foi fundado, em Lisboa, o Real Colégio dos Nobres, instituição que teria uma vida de sete décadas. No texto de fundação, expressavase a preocupação de criar uma zona de distinção para um grupo de alunos também distintos. À semelhança do que era comum em vários países da Europa, a consciência de que os estudos "se fariam mais férteis quando fossem cultivados em Colégios, nos quais a regularidade das horas, e a virtuosa emulação dos Estudantes" concorriam para um adiantamento nas profissões e uma maior disciplina, levava o legislador a percorrer o que havia sido a curta história do ensino de nobres em Portugal, para logo se deparar com um cenário de completo abandono, decadência e ruína (Carta de Lei de 7 de março de 1761). A solução parecia se encontrar num governo direto do colégio, interceptado apenas pela figura do reitor. Teria a seu cargo "o governo do Colégio" e seria "Pessoa de Letras, e Virtudes", castigaria os desassossegos e os barulhos, zelaria pela manutenção do asseio e da decência (Carta de lei de 7 de março de 1761). O espaço disciplinar dividia-se em parcelas de tempos, de espaços e de tarefas.

O número de pensionistas inicial contabilizava-se em cem, e as condições de admissão eram claras: saber ler e escrever, não ter menos de sete nem mais de 13 anos e, sobretudo, possuir o "foro de moço fidalgo" (Carta de lei de 7 de março de 1761). Toda a organização institucional revelava uma racionalidade disciplinar própria das instituições de carácter total (GOFFMAN, 1991), onde o parcelamento do tempo, a compartimentação dos saberes e a divisão do trabalho permitiam um isolamento do corpo de modo a transformá-lo em zona de intervenção.

Os planos de estudos eram extensos. Os alunos aprenderiam as Línguas Latina e Grega, Retórica, Poética, Lógica e História. Numa segunda fase, teriam as línguas francesa, italiana e inglesa. Aprenderam ainda Matemática, Arquiteturas Militar e Civil, e, finalmente, 
Desenho. Completava-se o rol de matérias com a Física e com as Artes de Cavalaria, Esgrima e Dança. A tipologia dos saberes que compunham esse menu de conhecimentos era produtora da própria distinção. O capital simbólico aqui mobilizado não deixa dúvidas relativamente ao campo de que é produto e que simultaneamente vai produzindo, muito principalmente em relação àquelas que eram entendidas como as artes liberais: andar a cavalo, lutar com a espada e dançar. As artes mostravam ser eficazes do ponto de vista da disciplina, do policiamento, do autogoverno dos sujeitos, mas só se impuseram à custa da sua própria legitimação como uma esfera superior da cultura, capaz de 'civilizar'.

Aqui, teremos que fazer uma paragem e pensar que a estruturação desse espaço de sensibilidade e de civilidade encontrava a sua própria possibilidade de existência nos espaços e nas figuras inventadas como contraponto da modernidade. Se a Europa aparecia como a parte do mundo distinta e civilizada, isso só aconteceu pela força de uma produção discursiva e por práticas de violência que categorizam as outras geografias como menos desenvolvidas, e outros povos e culturas como 'presos' numa espécie de infância da história. Contudo, e como nota Simon Gikandi (2011), a ideia de uma interioridade moderna, de um eu sensível e civilizado, e de uma cultura de gosto Europeu construíramse a par de práticas colonizadoras, do tráfico e da exploração de vidas, do roubo, etc. Dentro dos Estados-nação Europeus, os 'Outros' eram todos aqueles que poderiam facilmente converter-se em sujeitos sem governo. A ideia de uma cultura distinta, assente nas artes, surgiu assim para distinguir com base num monopólio de privilégios, e para regular formas de vida e de comportamentos.

Na reta final de vida do Colégio, em 1835, seria introduzida música vocal e instrumental. O monopólio dessas atividades pela classe nobre era convertido na própria nobreza de praticá-las (BOURDIEU, 1996). Ainda que as arquiteturas militar e civil fossem percepcionadas como próximas da matemática, era ordenado que se anexasse vizinhas do Desenho e que houvesse professores diferentes para cada uma das áreas. O professor de arquitetura militar ensinaria "as regras gerais da fortificação", os "diversos métodos regulares, e irregulares de fortalecer as Praças", "os modos de fazer, e defender um sítio", "as Fortificações dos Campos, e Exércitos". O desenho como instrumento facilitador da aquisição do saber era evidenciado:

[...] os irá costumando ao Desenho, pondo-Ihes diante dos olhos as Lições, que Ihes der executadas em pequenos modelos de madeira, à vista das quais lhes mostrará o uso, e a necessidade de cada uma das partes que os constituírem (Carta de lei de 7 de março de 1761).

Visava-se um ensino com uma forte ligação à realidade, por modo a anular o enfado dos nobres. O professor de arquitetura civil, depois dos conhecimentos e regras 
elementares, passaria à explicação das medidas e das proporções. De modo semelhante, o professor de Desenho ensinaria as noções e "principais medidas", as "respectivas proporções" que "constituem os fundamentos desta Arte". As aulas de arquitetura militar e civil organizar-se-iam pela manhã, nos dias determinados, e nessas tardes, com o auxílio do professor de Desenho, tentar-se-ia que se unisse a teoria à prática de modo a que os alunos formassem ideias "claras" e "distintas" do que se Ihes ensinava (Carta de lei de 7 de março de 1761).

O Colégio dos Nobres ver-se-ia extinto pelo decreto de 4 de janeiro de 1838 por não estar já em "harmonia com a constituição política da monarquia, em razão de ser por seu instituto uma escola privilegiada" (RIBEIRO, 1876, p. 322). Contudo, essa discussão já não era completamente nova. Ainda nos anos 20 do século 19, o parlamento português discute o caráter privilegiado do Colégio. Debruçaram-se sobre duas questões: a do pagamento aos professores com verbas do tesouro público e a extinção do estabelecimento. O colégio era então apontado como anticonstitucional por se dedicar "à instrução pública exclusiva de uma classe da sociedade". "E que se ensina lá? Filosofia, grego, latim, desenho, retórica, etc,", "até aqui vemos aulas de esgrima e dança, e o mestre das obras remunerado pelo subsídio literário". Ora, todas essas ciências não se ensinam em Lisboa em muitas aulas públicas e particulares? A resposta era simples. Quanto às verbas, o parecer era negativo. Os ditos nobres que fossem estudar "onde vão os mais". "Quem quiser mestres particulares que Ihes pague, que os cidadãos tenham bastantes escolas públicas onde aprendam" (debate parlamentar de 11 de janeiro de 1823).

\section{A Casa Pia de Lisboa: de 'marginais' a 'artistas'}

A Casa Pia de Lisboa, instituição portuguesa criada em 3 de julho de 1780 pelo Intendente Geral da Polícia Diogo Inácio de Pina Manique, constituiu-se como uma das primeiras instituições de acolhimento e regeneração de crianças e jovens hoje considerados como 'em risco' (MARTINS, 2009). Desde os seus alvores, a Casa Pia de Lisboa marcou a paisagem educativa portuguesa, configurando-se como um laboratório da modernidade pedagógica. Foi aí que se desenvolveu de modo sistemático o ensino das artes, então consideradas como um destino desejável para as crianças e jovens tutelados pela instituição, e onde o conceito de ensino integral do aluno adquiriu máxima expressão. Por outro lado, na Casa Pia desenvolveram-se técnicas disciplinares e de normalização da infância e juventude anormais e desviantes.

Revista Digital do LAV - Santa Maria - vol. 14, n. 2, p. 359 - 384 - mai./ago. 2021 ISSN 1983 - 7348 http://dx.doi.org/10.5902/1983734864729 
Na Memória da comissão que em 1821 era encarregada de visitar a Casa Pia de Lisboa pode ler-se que "havia nesta Casa Pia Mestres, que ensinavam a fabricar lonas, brins, cabos de laborar, tecidos de algodão, seda, meias, panos de linho, e fiações para estas diferentes manufacturas" (MACEDO et al., 1821, p. 408). Depressa acedemos a essa preocupação inicial da instituição em acolher e regenerar, por meio do trabalho, travando uma luta contra a ociosidade. Contudo, essa comissão elaborou uma crítica face aos métodos seguidos na Casa Pia de Lisboa, muito principalmente nas aulas de desenho. A mostrar clara consciência de que a economia pedia operários qualificados para as artes e ofícios industriais, sublinhou-se que a aula de desenho deveria limitar-se "aos princípios de desenho suficientes para cada um saber manejar o lápis para exprimir os objectos da sua profissão". Tratava-se de "criar artistas, e não pintores, e arquitectos" (MACEDO et al., 1821, p. 409). Os objetivos da instituição estavam traçados bem como os meios para atingi-los: ensinar a teoria necessária para as artes e que todo aquele que saísse da Casa Pia soubesse ler, escrever, e alguns princípios de desenho e de geometria. Eis o desejo: "que da Casa Pia saíssem homens capazes de executar uma máquina ainda que simples, sem destruir madeira e andar às apalpadelas" (MACEDO et al., 1821, p. 408-409).

Dizia-se, neste mesmo relatório, que no momento inicial da Casa Pia não era visível a regra de acolhimento, senão a regra da 'necessidade'. Em 1822, António José Pedroso de Almeida, escrivão da Fazenda da Casa Pia, entregava ao Diretor uma carta, na qual refletia sobre a reforma do estabelecimento. Nessa altura, não havia qualquer dúvida de que formar um Colégio de Artistas era o destino da Casa Pia.

As dinâmicas desenvolvidas neste contexto deixam-nos perceber uma progressiva afinação de tecnologias de governo, em expansão no movimento mais geral de afirmação dos Estados-Nação, diretamente relacionadas com a regulação do comportamento e da conduta dos seus primeiros internados e alunos. A organização do tempo e das tarefas, o isolamento e a vigilância estabeleciam-se como os primeiros mecanismos de produção de corpos 'úteis' e 'dóceis'. A teoria geral do adestramento, explica Michel Foucault (2004), é aquela que une ao corpo que é analisável, o corpo que é manipulável, que pode ser submetido e transformado e que, sobretudo, aprenderá a desejar para si mesmo, transformar-se profundamente.

A complexidade da instituição desenhava-se na tipologia das 'espécies' que acolhia, habitantes das franjas, mais próximos do louco e do criminoso do que da normalidade. Era essa, por si só, a razão mais do que suficiente para cuidar, corrigir e tratar. Nessa instituição, o gesto foi sempre levado em profundidade; acima de tudo, era esta uma casa onde a ortopedia moral se executava não somente pela imposição directa da disciplina, 
pela presença de todos os 'engenheiros' da alma (professores, psicólogos, médicos escolares), mas pela infiltração na alma do aluno, numa exposição permanente do seu 'eu', fosse no olhar que o objetivava como habitante da instituição (formas de notação, de registo, de representação, de acumulação e de circulação de saberes sobre o aluno, projetando imagens daquilo que cada um deles deveria ser), fosse, progressivamente, pelos hábitos de trabalho e mecanismos ativadores da introspecção.

Tratava-se de corrigir, normalizar, domesticar, mas sempre através do funcionamento de técnicas que despoletariam no sujeito uma vinculação e uma vontade de transformação num outro sujeito socialmente enquadrado e profissionalmente produtivo. Como 'estufa' para mudar pessoas (GOFFMAN, 1991), a Casa Pia conseguiu reunir o substancial da cela prisional, da oficina e do hospital. Importava treinar o aluno casapiano de uma forma também ela total: trabalhar as faculdades da alma, a inteligência, a sensibilidade e a vontade.

Em 1859, José Maria Eugénio de Almeida foi nomeado provedor da Casa Pia de Lisboa. A ação do provedor fez-se sentir, para além da intervenção direta na higienização do espaço, na reelaboração do plano de estudos. Concentrou-se na instrução primária elementar. Era nesse intervalo de dois ou três anos, no qual os alunos se preparavam a nível elementar, que se deveria então "consultar a experiência das aulas ultimamente criadas e aproveitar os ditames que ela for ensinando para organizar o resto do ensino". Assumia que esse era um processo "parte de um plano" que mais tarde se desenvolveria e se completaria e falava de uma educação útil. Reformaria a aula de desenho, "dando-lhe uma feição mais congruente com as aplicações que deve ter nas futuras ocupações dos alunos" (ALMEIDA, 1861, p. 71-72).

Em 1866, José Maria Eugénio de Almeida nomeou José António Simões Raposo como provisor de estudos. No Relatório que Raposo escreveria a propósito dos seus três primeiros anos de trabalho no plano de estudos da Casa Pia, depois dos comentários tecidos a propósito da transformação da Casa Pia empreendida por Almeida, dedicava-se a elaborar princípios que presidiram ao seu exercício para a educação física, intelectual, moral e religiosa. No seu discurso, começava a materializar-se aquela que viria a instalarse definitivamente como a gramática da modernidade escolar. Do ponto de vista pedagógico, começava por estabelecer horários, a graduação dos exercícios, as recompensas e as punições:

Todo o meu sonho dourado é chegar a um dia em que o professor tenha tudo feito na sua aula; colecções de problemas graduais em extensão e intensidade e relativos a todos os assuntos dignos de serem tratados na escola prática e racional; colecções de assuntos

Revista Digital do LAV - Santa Maria - vol. 14, n. 2, p. 359 - 384 - mai./ago. 2021 ISSN 1983 - 7348 http://dx.doi.org/10.5902/1983734864729 
próprios a desenvolver a inteligência, o senso prático das crianças, e a despertar-Ihes no coração os sentimentos da honra, do trabalho, da economia, da justiça e da caridade; mas assuntos escolhidos, e gradualmente transmitidos, ora intuitiva ora analogicamente ao ânimo e à consciência das crianças, assuntos tirados da vida usual, dos seus próprios brinquedos, das suas triviais ocupações e finalmente de tudo o que possa ser aplicado à vida real (RAPOSO, 1869, p. 15).

A Casa Pia de Lisboa invertia a racionalidade do que até aí havia sido todo o ensino em Portugal. Ela era, certamente, e uma vez mais, o laboratório da sociedade portuguesa, transparecendo no discurso aí produzido influências internacionais no modo como a educação se imaginava articulada com um saber específico sobre a infância. Ao nível da organização da aprendizagem, aquilo que antes começava do 'desconhecido para o conhecido', era agora preconizado 'do conhecido para o desconhecido', o que antes era 'do difícil para o fácil', agora o era 'do fácil para o difícil', "da memória sacrificada para o esquecimento imediato, do inferno real para o céu apenas entre-sonhado", agora seria mais correto dizer-se "da satisfação para a alegria, da compreensão que percebe para a memória que retém, da verdade natural para a verdade prática" (COSTA, 1870, p. 122). Implantava-se, no tecido português, "a escola do século XIX!... a escola do futuro!" (RAPOSO, 1869, p. 19).

A educação era abordada pelo provisor de estudos em seis áreas que, embora comunicantes entre si, particularizaram-se no seu alcance: educação dos sentidos, educação física, educação intelectual, educação moral, educação econômica e educação social.

No caso do desenho, iniciava-se o discurso pela justificativa da consideração do desenho como necessário e indispensável ao cidadão do século 19 e do futuro, ora pelo lugar que ocupava no mundo da indústria, ora pelo papel regulador e moralizador que cumpria. Todos, sem exceção, precisam do desenho. As ideias não poderiam existir no espírito sem o auxílio das formas. Os professores precisavam do desenho, os discípulos precisavam do desenho:

O bom professor apresenta primeiro o objecto que representa a ideia, que deseja transmitir aos seus discípulos, [...] mostra-Ihes em relevo em estampa, ou desenhada no quadro preto a sua imagem; $[. .$.$] recorre à analogia, [. .$.$] e só quando nenhuma destas$ intuições pode empregar é que recorre à descrição; a qual ainda assim faz com que seja revestida de mil imagens vivas, de mil comparações apropriadas. Eis aqui a utilidade do desenho para os alunos, e como nas mãos do professor se torna um instrumento poderoso da arte espinhosa e difícil do ensino (RAPOSO, 1869, p. 165).

Revista Digital do LAV - Santa Maria - vol. 14, n. 2, p. 359 - 384 - mai./ago. 2021 ISSN 1983 - 7348 http://dx.doi.org/10.5902/1983734864729 
Toda a elaboração conceptual do programa enfileirava pelos métodos de uma pedagogia que se queria moderna, resgatando os exemplos de Johannes Pestalozzi e de Friedrich Froebel e traçando caminhos que tinham na intuição e nos percursos progressivamente graduados a sua rota. Citavam-se os compêndios de M. Ghyra e de Teodoro da Mota que eram vistos como os precursores, em Portugal, dos novos métodos. A revolução da Casa Pia era, aliás, vista por António da Costa, como a revolução contra a rotina, revolução que assentava em três princípios: "nos métodos, nos métodos e nos métodos" (COSTA, 1870, p. 124).

O desenho que, pelos anos 60 do século 19, dominava a paisagem casapiana era um desenho "sui generis". Nem era a "teoria das sombras", tampouco a "teoria das leis e projecções". O que se pretendia era que os alunos 'contornassem' "um objecto", que soubessem 'manejar' "uma régua, um esquadro, um compasso e um lápis" e que se aventurassem a riscar com precisão e saber "mapas" e "contas correntes". Incentivava-se um desenho aplicado a todas as esferas da vida e que os alunos soubessem, enfim, traçar ângulos, linhas e polígonos, que a caligrafia fosse ela própria uma arte de desenhar e que se expulsasse, da escola primária, o desenho figurativo, o qual não revelava nem "utilidade próxima, e nem remota talvez" (RAPOSO, 1869, p. 166).

Feito o ensino individualmente, devidamente explicado, como era o caso do ensino do desenho, no qual o professor explicava aos alunos a razão de ser das formas, também o ensino dos ofícios seria explicado e exemplificado a cada aluno, o que tornaria um ensino mais 'perfeito', 'profícuo' e 'rápido'. Francisco Margiochi iluminava, já duas décadas depois do plano traçado por Eugénio de Almeida e Simões Raposo o que propunha de novo para a instrução nos ofícios, de acordo com aquilo que a prática no 'mundo civilizado' a cada momento mostrava (MARGIOCHI, 1893). Pelo retrato que fez da instituição D. António da Costa, entusiasmado com a transformação da Casa Pia operada às mãos de António Eugénio de Almeida, diríamos que neste viveiro se foram produzindo cidadãos verdadeiramente modernos, isto é, nativos na língua da indústria que o século 19 vulgarizaria: o desenho. Reportava-se à participação da Casa Pia de Lisboa nas duas Exposições Internacionais, a de Viena de Áustria, em 1873, e a de Paris, em 1875. "Atraíu as vistas" e em ambos os certames "foi premiada como estabelecimento educativo" a par dos mais notáveis institutos "das nações civilizadas" (COSTA, 1870, p. 130-131). Os trabalhos de desenho linear aí expostos eram louvados, bem como os de máquinas e de arquitetura. 


\section{O desenho como sublime tecnológico da nação}

Ao longo da segunda metade do século 19, o desenho foi-se progressivamente assumindo como uma língua necessária ao desenvolvimento das nações em processo de industrialização. A ideia do desenho como língua é apresentada por Molly Nesbit (2000) em um trabalho que toma por ponto de partida o ensino do desenho na França durante o século 19 e inícios do século seguinte. Para a autora, a necessidade do ensino do desenho transformou-se num senso comum, dito por outras palavras, houve um momento a partir do qual a ideia de que aprender a desenhar era não só necessário, mas antes reflexo de uma modernidade. Diria Silvestre Ribeiro, em Portugal, que "nos tempos passados o desenho foi considerado como sendo uma arte de mero recreio, quando, aliás, e pela natureza das coisas, é uma língua universal e indispensável" (RIBEIRO, 1873, p. 61). O desenho transformava-se na língua da indústria, para a qual era urgente criar uma gramática, e, com isso, no novo sublime tecnológico das nações que se consideravam civilizadas.

Nos Estados Unidos, Benjamin Franklin, em 1749, propunha, na esteira do pensamento de John Locke, que o desenho se institucionalizasse como parte da educação de todos, especialmente a partir de cópias de estampas e de estudos de perspectiva. $\mathrm{O}$ desenho tomava-se como uma língua universal, entendido por todas as nações, e aí se encontrava a razão da sua utilidade tanto na educação do operário quanto do nobre:

Drawing is no less useful to a Mechanic than to a Gentleman. Several Handicrafts seem to require it; as the Carpenter's, Shipwright's, Engraver's, Painter's, Carver's, Cabinet-maker's, Gardiner's, and other Businesses. By a little Skill of this kind, the Workman may perfect his own Idea of the Thing to be done, before he begins to work; and show a Draft for the Encouragement and Satisfaction of his Employer (FRANKLIN, n.d., p. s/p).

Aquilo a que assistimos, portanto, é a um dos lados do pensamento sobre a necessidade de uma educação artística, que foi ganhando forma num debate que diríamos o mais científico possível e que foi crescendo no seio das ciências pedagógicas, ao mesmo tempo em que coexistia a ideia de que a arte ultrapassava objetivos puramente funcionais.

David Kamens e Yun-Kyung (1992), que estudaram a progressiva introdução de novas disciplinas no currículo escolar moderno, falam da educação artística e da educação física como estando no centro dessa inovação. A justificativa da necessidade da arte naquela que pretendia ser uma escola de massas não tardou, muito embora o tema tenha se tornado uma luta que encontrava bloqueios sucessivos na arena da política e na continuada acusação do baixo nível cultural do país, mas que encontrava, também, no potencial do progresso uma mola impulsionadora para a mudança. Num discurso pronunciado na Academia de Belas Artes de Lisboa, em 1862, por ocasião da distribuição 
dos prémios, o professor da mesma Academia, Francisco de Assis Rodrigues, falava nas artes plásticas como uma 'linguagem universal'. E era no desenho que encontrava o elo unificador:

Não é o estudo das Artes do Desenho também muito útil às artes mecânicas, ou ofícios fabris? Ah! que vasto campo se abre agora a meus olhos, quando considero nas utilidades que as Artes fabris e industriais colhem das Artes plásticas! Elas não só concorrem para a educação das pessoas civilizadas, que devem aprender o Desenho, como Platão diz que aprendera, junto com as mais sublimes ciências, a fim de se habilitar a bem julgar do belo, mas também devem fazer parte da instrução dos povos (RODRIGUES, 1862, s/p).

O consenso era que o desenho seria essencial à formação dos artistas e dos operários. A promessa era a de que a linguagem das formas poderia organizar-se segundo uma gramática de alcance universal e comum a toda a educação e, mais tarde, especializar-se por níveis e adequar-se às diferentes profissões, começando pela linha e fazendo da arte a educação primária do homem do mundo, do trabalhador e do artista (NESBIT, 2000, p. 23-24). O mesmo princípio que presidia à formação das línguas era o que deveria seguir-se para a elaboração do desenho como uma língua. A geometria não existia senão no interior da linguagem da arte e era ela a gramática de toda a forma. Ponto, linha e plano juntavam-se como as peças que permitiram montar um puzzle completo que poderia ser a representação da totalidade do mundo. As constelações, as analogias, as trajetórias do pensamento que se depositavam no desenho constituíam-no como o instrumento para a duplicação do mundo, uma espécie de arquivo do visível, cuja ordem se fixava na infinitude de recombinações da geometria. A geometria conformavase como a medida própria aplicável a tudo, dos objetos, à natureza, à própria alma e ao pensamento. Aplicar ao olho a geometria como uma lente parecia configurar-se como uma das fórmulas do século. Os conceitos envolvidos eram simples: vulgarizar e tornar útil. Educar o olhar e treinar a mão. Formar gênios não seria, nunca por nunca, o objetivo da educação, mas antes o de produzir homens hábeis, praticantes capazes e bons espíritos. De modo bastante claro anunciava-se que o objetivo principal era da ordem do adestramento:

[o desenho] Exercita o aluno na justa apreciação das distâncias, dimensões e formas dos objectos, adestrar-Ihe a mão no hábito de reproduzir esses objectos com exactidão perfeita, mediante o lápis; - auxiliá-lo a formar cabal ideia de tudo que vê, notando-lhe as dimensões, as diferenças e analogias; - exercitá-lo depois a reproduzir essas mesmas formas, principiando pelas mais fáceis, e passando gradualmente às mais complicadas (BRANCO, 1886, p. 628).

Esse saber fazer encontrava-se então configurado pela ordem do discurso pedagógico e psicológico. A alquimia das disciplinas escolares transporta os saberes da 
arte para a psicologia da criança e do jovem. A transformação mágica a que se refere Thomas Popkewitz (2004), que ocorre na viagem dos saberes para o quadro escolar, é marcada pelas expectativas construídas em torno das concepções de infância ou adolescência cujo objetivo principal é governar o aluno, transformando-o num sujeito ativo e capaz de 'resolver problemas'. No design do saber estão contidas as partículas do design das disposições e das sensibilidades do aluno. Assim, o discurso pedagógico sobre o desenho alicerça-se num saber sobre quem as crianças e os jovens são e, desse modo, produz e reproduz as qualidades que estas terão de ter no futuro. Nesse processo, fabricam-se tipos de pessoas administráveis enquanto cidadãos. Tornando a criança no campo de governo, uma necessária estabilização dos saberes torna-se necessária, e por isso, não nos parecerá ainda hoje totalmente estranha a metodologia apresentada há mais de um século:

Fazei depois traçar toda a sorte de linhas, triângulos, quadriláteros, polígonos, figuras geométricas, cubos, prismas, cones, etc, coordenando-os simetricamente, por maneira agradável de ver-se. Depois, fazei desenhar brinquedos pueris, instrumentos de jardinagem, utensílios, flores, folhas, uma rocha, um lanço de parede, enfim, todos os objectos de agrado do menino, guiando-o assim à aquisição de conhecimentos novos (BRANCO, 1886, p. 628).

Pelo exercício atrás descrito, o leitor de hoje tem acesso à historicidade do seu próprio presente. Mas mais familiaridade sentirá, e simultaneamente, estranhamento, quando se confrontar com a divisão, a crescente complexificação e os métodos de ensino que configuravam a ordem do discurso do ensino do desenho. A hibridação entre as finalidades desse ensino na construção de sujeitos disciplinados e o lugar ocupado na rede 'simbólica' das aprendizagens artísticas torna explícita a necessidade de abandonarmos os mundos de clivagens entre a liberdade e a disciplina, entre o governo e a autonomia dos sujeitos. Em plena segunda metade do século 19, não havia polícia discursiva que inibisse o dictum de que o exercício do desenho era como uma ginástica que deveria ser imposta aos alunos, logo, só o muito treino conduziria a um domínio pleno de si:

O professor deve impor aos seus discípulos, como uma ginástica preparatória e indispensável destinada a exercitar o seu golpe de vista relativamente à primeira das três dimensões, o comprimento (BRANCO, 1886, p. 629).

A nova ordem da visão fabricava-se no interior daquilo que constituía o próprio discurso pedagógico sobre o desenho. O exercício visto como a contínua exposição à observação ou como a repetição do fazer assumia-se como a regra.

Do que se tratava era de incorporar a visão como propriedade física do sujeito e, logo, como campo de governo. Dizer isto não era reduzir o ver à propriedade fisiológica, 
mas abrir a possibilidade de modificar e ampliar essa propriedade. O que aqui há a destacar é a possibilidade de aprender a desenhar e apreender uma panóplia de formas pela entrega absoluta ao exercício da observação e ao treino da mão. A vinculação da atenção a essas tarefas seria a chave para o autogoverno do estudante e para uma literacia que então se transformava no grande senso comum da indústria. Aprender a ver perpetuava-se como o primeiro objetivo. Para atingi-lo, só um treino intenso nas propriedades da linha, das medidas, dos ângulos e das orientações.

Tanto na prática como na teoria, a geometria grassava como a base do desenho. Como observa Molly Nesbit (1986), a linguagem segundo a qual era imaginada a aprendizagem do desenho, e o princípio segundo o qual assentava a sua necessidade na vida moderna, baseava-se numa estética de neutralidade, configurada, contudo, de acordo com um regime de visibilidade e visualidade particulares. Antes de Cézanne ter proclamado a importância do cilindro, da esfera e do cone como os três elementos capazes de tudo conter e de tudo gerar no mundo da visualidade, esse era o senso comum da aprendizagem técnica do desenho. Essa neutralidade afirmava-se pelo seu carácter não retinal. A verdade dos objetos representados, fosse num desenho que procurasse captar a superfície dos objetos, fosse no mecânico e de perspectiva, não era óptica. Do que se tratava, no discurso daqueles que defendiam o ensino do desenho como uma ferramenta e como uma linguagem de uso diário, era de defender uma linguagem de trabalho aplicável à nova linguagem industrial. Era a sua capacidade para criar progresso que fazia do desenho o sublime tecnológico do século 19 e, sobretudo, mais do que ideias, a possibilidade de expressar 'coisas'.

\section{O desenho industrial: a gramática da máquina}

É no contexto do desenho como o sublime tecnológico do século 19 que, em 1836, ano da fundação das Academias de Belas Artes, o legislador vem também criar o Conservatório de Artes e Ofícios de Lisboa (PORTUGAL, 1836) e o Conservatório Portuense de Artes e Ofícios (PORTUGAL, 1837). No que respeita ao Conservatório da capital, cujos princípios se manteriam para o Porto, abria logo o respectivo decreto estipulando a natureza e fins de tal espaço: "Formar-se-á em Lisboa um depósito geral de máquinas, modelos, utensílios, desenhos, descrições, e livros relativos às diferentes Artes, e Ofícios" (PORTUGAL, 1836).

Que este seria, portanto, o museu-arquivo da indústria e da arte a ela aplicada, tanto ao nível de uma coleção de máquinas e dos seus múltiplos objetos afins, quer de 
modelos, de desenhos e de descrições, bem assim como de livros. Muito embora esta descrição se inicie pelas máquinas, o certo é que já aqui se denota que um eixo central passava pela própria gramática da máquina no sentido da sua conceptualização e produção. O horizonte da invenção perpassava nas palavras do diploma legal. Uma só sala, ou mais do que uma, deveriam ser reservadas para se guardarem "as máquinas, ou artefactos para no futuro se inventarem dentro do país" e o seu inventor teria a "obrigação de depositar na Sala Pública de exposição geral um modelo, desenho, ou descrição do seu invento", iluminando-se assim o processo criativo (PORTUGAL, 1836). É neste cenário de clara consciência de que o progresso passaria inevitavelmente por uma qualificação técnica dos ainda escolares portugueses que se vem apresentar, em Dezembro de 1852, e sob o nome de Fontes Pereira de Melo, o ensino industrial nas duas principais cidades do país (Lisboa e Porto).

Numa cronologia histórica, 1852, terá sido o ano em que se implantou o ensino industrial em Portugal, pela criação do Instituto Industrial de Lisboa e da Escola Industrial do Porto. De muito antes, contudo, datam as preocupações de conceber um ensino técnico que, no seu carácter, fosse capaz de fazer frente às necessidades de produção que as sociedades e economias nascentes na modernidade impunham. A modernização que se impunha um pouco por toda a Europa mostrava que era por uma política de organização a partir da base da aprendizagem, que o desenvolvimento econômico teria lugar. Caldeavam-se princípios de governo com princípios econômicos e com princípios estéticos, naturalizando a ideia de que a arte e o seu saber, muito para lá das artes maiores, belas artes, que eram como que o embaixador desse pensamento pelo seu carácter 'elevado', assumiam-se como o vector estratégico na educação das massas. O domínio do desenho como uma nova língua que todos deveriam aprender transformou-se então no topoi do século 19, muito embora tenha oposto, a respeito dos métodos, diferentes concepções do que seria esse desenho.

O Estado vê-se então perante a obrigação de responder face às mudanças no mundo do trabalho, garantindo não apenas a preparação dos futuros trabalhadores, mas mais do que isso, garantindo a produção de sujeitos capazes de se introduzirem na nova disciplina da fábrica. Aquilo a que começamos a assistir é ao desenvolvimento de uma nova literacia, não apenas visual, mas técnica. A literacia técnica envolvia o domínio de quatro sistemas de notação e seus respectivos vocabulários e gramáticas: a expressão alfabética, as notações científicas, as notações matemáticas e a representação gráfica e espacial de objetos (STEVENS, 1995, p. 2). Era sob esta nova literacia, particularmente repousando sobre o desenho, que começava a emergir o discurso do progresso, reunindo-se a fábrica, a oficina e o atelier. A este conhecimento considerado útil juntava-se também o horizonte 
do desenvolvimento cognitivo dos futuros operários e a linha da moralidade. O ensino, quando "bem orientado, é o maior moralizador do povo", desse modo deveria mobilizarse para fornecer uma organização perfeita e dispor dos meios necessários para exercer "a sua acção proficuamente". "Um ensino mau e incompleto", advertia o legislador em 1918, "poderá ser prejudicial para o cidadão, mas é sempre perigoso para o Estado" (PORTUGAL, 1918). A disciplina da oficina, do atelier ou da fábrica tem por fim fabricar um corpo capaz de responder com eficiência, como se ele próprio fosse uma das peças de uma máquina multissegmentar. Os hábitos da disciplina, da circunspecção e da reflexão permitem desenvolver as bases de um cidadão moralmente enquadrado. É este o dispositivo no qual se enquadra, aqui, a introdução do desenho numa educação que queria abranger o maior número. Eram esses, essencialmente, os filhos das classes populares. E era este o aluno imaginado e o seu processo de formação:

Toda a mira dos legisladores da nossa redenção industrial deve ser esta: tornar o ensino prático, pela anexação quanto possível estreita da aula à oficina, e prender as incontestáveis aptidões do operário à tradição histórica das antigas indústrias e manufacturas portuguesas [...]. Uma vez familiarizado o aprendiz com os rudimentos científicos e gráficos do curso, feita a mão no desenho, e o olhar nos segredos da perspectiva, valorização da cor, e apercepção geométrica e estética do objecto a copiar ou a criar, para fazer dele um operário correcto, ou um artista agilíssimo e elegante, imperetrível se torna chamá-lo a um campo de criação onde as suas faculdades inventivas tomem voo, variando ao infinito as concepções, e evitando que os próprios velhos tombem no ramerrão deletério das reedições maquinais, antagónicas de todo o progresso, e desonra de uma nação que se preze industrial (ALMEIDA, 1892, p. 341).

\section{O desenho técnico em finais do século 19: um desenho 'quase' futurista}

Ah, poder exprimir-me todo como um motor se exprime! Ser completo como uma máquina! (PESSOA, 1915, p. 77)

Por alterações significativas que vem apontar, principalmente relativas ao desenho, e à introdução dos trabalhos manuais nos programas das escolas industriais, seguiremos por ora o decreto de 5 de outubro de 1893. Neste documento, dividia-se o desenho geral elementar em duas classes, a primeira de dois anos e a segunda, de três. Começava a prescrição curricular para o primeiro ano por um "conhecimento intuitivo dos corpos, das superfícies, linhas e ponto" (PORTUGAL, 1893). Os elementos básicos da linguagem visual faziam explicitamente a sua entrada, começando a cristalizar a gramática da modernidade do ensino artístico. Os limites e os volumes dos corpos, as superfícies, as suas dimensões e seus limites, bem como as linhas e as suas dimensões, nas suas ramificações de linha 
recta, quebrada e curva.

Linhas horizontal e vertical, perpendiculares e oblíquas, linhas paralelas. O ponto. O desenho à vista, através de cópias de "figuras feitas na pedra pelo professor à vista dos alunos" de linhas retas, e de sólidos geométricos, somente à vista. Primeiro o cubo, o paralelepípedo, o prisma e a pirâmide, de seguida, o cilindro, o cone e a esfera. Todos os desenhos foram realizados a carvão e a lápis. Juntar-se-ia à lista dos resultados a atingir o do "conhecimento intuitivo da perspectiva" (PORTUGAL, 1893). Aos exercícios de combinações e aplicação simples das linhas e dos polígonos, bem como da circunferência, somavam-se os exercícios em cartão, de construção de sólidos geométricos.

Seguia-se a etapa seguinte, a demonstrar que o ensino se fazia de forma progressiva, não contemplando, ainda, a idade física e mental dos alunos. Contudo, era a entrada pela graduação dos exercícios que determinava a sua eficácia disciplinadora. Introduzido aos instrumentos auxiliares do desenho geométrico - régua, compasso, esquadro, transferidor -, e depois de verificá-los, a sua utilização entraria no traçado das paralelas, perpendiculares, marcação de ângulos, polígonos diversos, gregas e meandros. Nos exercícios anteriores de perspectiva era dada continuação, mas acompanhando-os de uma maior diversidade: elementos simples de arquitetura e vasos simples. Os sólidos geométricos em cartão seriam retomados, mas "aplicados a casos gradualmente mais complicados" (PORTUGAL, 1893).

Para a II classe, $3^{\circ}$ ano, insistia-se nos exercícios de perspectiva, agora tendo por objeto grupos de sólidos e objetos de uso comum. As noções da geometria plana, projecções e planificações, exercícios simples de perspectiva cavaleira. Para que se adaptasse à indústria era preciso que o aluno compreendesse o vaivém entre o objeto e a sua tradução no plano do desenho, de modo rigoroso. Apareciam as escalas, o compasso de proporção, as figuras simétricas e as semelhantes, o círculo e os círculos tangentes, as tangentes e as secantes. O desenho como uma língua que não seria estranha à matemática. A oval, o óvulo, as espirais, a elipse e os processos de traçá-las. Constantemente se lembrava da aplicação a exemplos sempre 'mais difíceis'. Para o $4^{\circ}$ ano, que se manteria para o $5^{\circ}$, o desenho de ornato, num primeiro momento "à vista de modelos estilizados", quer de folhas, quer de frutos, ou de motivos decorativos, os quais, no $5^{\circ}$ ano, seriam "motivos decorativos nacionais", a carvão, lápis e esfuminho. O lápis e as aguadas exploravam-se no desenho à vista de modelos a partir de trechos arquitetônicos. Subitamente entravam as "peças e órgãos de máquinas e ferramentas", também para desenhar à vista, e os exercícios de modelação, igualmente graduados, e que deveriam evoluir em paralelo com o desenho. No $5^{\circ}$ ano, preconizava-se o uso da 
estampa cotada, tanto para os "cortes e ligações de madeira", quanto para os "objectos de ferro de uso comum" (PORTUGAL, 1893). Sucediam-se elementos que assentavam certamente na cultura visual dos alunos. Grades de jardim, balcões, etc. Ainda, o desenho rigoroso e à vista de móveis cujos modelos fossem simples. Que o desenho era uma língua, a da indústria, das artes e dos ofícios, já não era estranho, mas que fosse ensinado como uma língua estrangeira era aquilo que toda essa subdivisão e compartimentação dos saberes evidenciavam.

Frases curtas, concisas e objetivas configuravam os programas curriculares do desenho no ensino técnico. A figura humana e a paisagem desapareciam do $3^{\circ}$ ano, depois de uma passagem fugaz pelo segundo. E não voltavam a aparecer, nem no desenho arquitetural nem no mecânico. De resto, Joaquim de Vasconcelos, por exemplo, marcaria o seu posicionamento contra a introdução da figura humana no desenho industrial. Em 1891, a propósito da Exposição das escolas industriais, diria que "a figura humana não pode nem deve entrar em semelhante desenho senão como elemento simplesmente decorativo, aliás, teremos um ensino híbrido, que não será nem académico, nem industrial" (VASCONCELOS, 1891, p. 9-10). Esse era um núcleo a desenvolver somente no ensino artístico de belas artes sob o risco de se incorrer em confusões e erros quanto à natureza de cada tipo de ensino.

O grande objetivo era colocar o aluno a observar. Treinar o olhar, fazer a mão. Governar o olhar por métodos e processos de representação e por modelos que se encaixavam, como entradas de dicionário, e se completavam pela sua aplicação e conhecimento da gramática das formas. As lições de desenho assemelhavam-se às lições de coisas. Cada objeto, todo o objeto, inclusive o próprio corpo, era passível de ser representado, planificado, fragmentado, pensado e reconhecido no interior dessa língua que era o desenho e de voltar à realidade pela sua construção efetiva. Mas o desenho era a realidade objetiva, a verdade dos objetos, e no desenho mecânico penetrava-se na verdade mais íntima deles. Para lá dos elementos formais da linguagem visual (ponto, linha, planos, superfícies, intersecções entre eles), repartia-se, dividia-se, nomeava-se cada órgão de cada máquina. Como num corpo, procedia-se à dissecação total dos objetos, à sua medição e representação:

Máquinas simples, alavancas, balanças, roldanas, sarilhos, guinchos e guindastes. Plano inclinado, parafuso, cunha, etc. - Trabalho mecânico. (...) ferramentas e orgãos elementares das máquinas (...). orgãos de ligação: rebites e cravações, parafusos diversos, chaves e chavetas; orgãos de vedação: tubos e suas ligações, válvulas e torneiras, cilindros, embolos, etc. orgãos de tracção: cordas, cabos, correntes, ganchos, etc. (...) moentes diversos, munhões, eixos de transmissão, uniões fixas, articuladas, de

Revista Digital do LAV - Santa Maria - vol. 14, n. 2, p. 359 - 384 - mai./ago. 2021 ISSN 1983 - 7348 http://dx.doi.org/10.5902/1983734864729 
engatar e de desengatar, de friç̧ão; mancais e caixas de untura diversas; cavaletes, suportes, consolas, pendurais, suportes articulados de Seller, Kuhn, Lorenz, etc.; tambores e correias, roldanas, rodas de engrenagem cilíndricas e cónicas diversas; parafuso sem fim; roda helicoidal; manivelas e excêntricos, tirantes, cruzetas e paralelas (PORTUGAL, 1893).

A enumeração de cada peça não anda longe da poesia futurista do elogio das máquinas, mas era preciso voltar ao conhecimento preciso e objetivo. Essas máquinas, contemporâneas, deveriam ser desenhadas rigorosamente a partir do natural. E a testagem do saber, pela cópia de máquinas completas, agora já unidas nas suas peças. Máquinas e desenhos funcionais!

\section{O Desenho na viragem para o século 20: a Reforma de Jaime Moniz}

Até 1895, os programas de desenho, no que ao ensino liceal diz respeito, resumiram-se à apresentação de listas de conteúdos a ministrar ou simplesmente à sua enunciação. Em 1836, o decreto que reforma a Instrução Secundária, colocava o desenho par a par com a aritmética, a algebra, a geometria e a trigonometria (PORTUGAL, 1836).

Em 1844, a Reforma da Instrução Pública decretava, para a instrução primária, mas somente no seu segundo grau, o 'desenho linear' e para as meninas especificava-se "os lavores mais usuais para o sexo feminino". Relativamente à Instrução Secundária definiase "a aritmética e geometria com aplicações às Artes, e primeiras noções de Álgebra" e, excepcionalmente no Liceu de Lisboa, abria-se a "Geometria e Mecânica aplicada às Artes e Ofícios" (PORTUGAL, 1844). Em 1860, o Curso Geral dos Liceus passava a incluir o 'Desenho linear' com duas aulas por semana (PORTUGAL, 1860). O Desenho manter-se-ia constante até final do século.

Mas em 1895, ficariam expressos, para o ensino secundário, os princípios totalmente de matriz moderna, relativamente ao ensino do desenho. Aqueles que se manteriam até que a psicologia viesse, no caso do desenho e dos trabalhos manuais, com uma acentuada carga na expressividade, na interioridade e no 'eu' do aluno, colocar-se na voz dos educadores mais próximos da segunda metade do século 20, alargando-se a amplitude da governamentalidade que já então ecoava.

Jaime Moniz, autor da Reforma que por ora nos ocupa, afirmava que todos os interesses de que dependeria "a formatura do homem policiado" estariam patentes na estruturação do ensino. O que pretendia com a sua reforma era que "os dois lados da cultura, o humanista e o real, e ainda as artes e as aptidões práticas" nela tivessem 
cabimento (MONIZ, 1918, p. 409). Era então que viajava ao exemplo alemão para mostrar, apoiando-se em Rein, a lógica do esquema do ensino secundário:

Ao lado do ensino ético o ensino estético, como requer a razão psicológica: o bem e o belo relacionam-se no fundo tão estreitamente que pode atribuir-se-Ihes a mesma origem, embora entre os dois avultem diferenças que conferem mais valor ao primeiro, o qual é por sua natureza imperativo e categórico: ninguém é obrigado a ser artista: a todos corre o dever de praticar o bem. Mas ao lado da cultura do bem a cultura do gosto. [...] Enfim deve considerar-se componente do plano o ensino do trabalho manual, que entra como ensino do desenho e modelação na divisão humanista e acompanha o estudo das ciências da natureza enquanto completa com a necessária prática da geografia, geometria, física e química, etc., o respectivo ensino teórico, no jardim da escola e no laboratório escolar (MONIZ, 1918, p. 411).

Encontrava-se justificada a presença das matérias artísticas na instrução secundária, e a elas se atribuíam territórios periféricos à sala de aula, mas de extrema importância para a produção de um saber sobre o aluno, quer 'no jardim da escola', quer no 'laboratório escolar'.

Esboçados os princípios e as linhas que teciam o ensino secundário, especificavase, para cada disciplina, a sua duração, uma hora de lição, à excepção do desenho que se estendia por hora e meia, para as duas primeiras classes, e por duas horas, nas classes imediatas, ainda que fosse empurrado para as margens do dia. O seu ensino seria sempre ao final da tarde. A inscrição dessa disciplina nos planos de estudos era deixada também para o final, e iniciava-se com a apresentação de quadros com os conteúdos a ministrar, bem como a sua anexação às diferentes classes e tipos de desenho estabelecidos: desenho rigoroso e desenho à vista.

Ficava claro nesta Reforma que o objetivo do desenho não era o de "educar os olhos e o gosto na apreciação das formas, das cores e da distribuição da luz, e habilitar a mão a exercer as correspondentes operações gráficas", muito maior era o seu alcance e sem divagações cromáticas: "desenvolver os poderes de análise e de síntese do espírito" e "socorrê-lo para os estudos geométricos e outros do quadro secundário". A sensação era também a de que o desenho era uma disciplina especial, aquela que, na colecção de disciplinas liceais, apresentava uma maior "maleabilidade", o que logo a fazia portadora de uma 'justeza' absoluta para se adaptar ao "desenvolvimento intelectual dos alunos" e a mais adequada "quando a cultura do intelecto" se revelava "espinhosa" (PORTUGAL, 1895). Era o desenho que representava a salvação, pelo seu caráter simultaneamente intelectual e pragmático.

Revista Digital do LAV - Santa Maria - vol. 14, n. 2, p. 359 - 384 - mai./ago. 2021 ISSN 1983 - 7348 http://dx.doi.org/10.5902/1983734864729 
O que então se tornava evidente no corpo deste texto legislativo era "a língua pedagógica comum", como chamou Jorge Ramos do Ó (2003b, p. 10) a essa forma de falar que passa a ser partilhada por todo um conjunto de experts que invadem a paisagem pedagógica de novecentos e se instalam para os tempos que se seguem. E como também o desenvolveu Nikolas Rose (1990), a partir de Foucault, a ideia de que o governo dos sujeitos passaria a depender de um conjunto de imagens, produzidas pelas ciências psicológicas, médicas e pedagógicas, que informam as subjectividades e promovem a regulação. Toda a metodologia seguida assumia a graduação, o carácter progressivo da aquisição das aprendizagens, do simples para o complexo. Na exposição oral, o professor não empregaria forma alguma 'dogmática'. Era na sequenciação dos factos, "à semelhança de premissas" que tornaria "as conclusões intuitivas" (PORTUGAL, 1895). O mesmo seria dizer que, na figura do professor, depositava-se a obrigação de traduzir a viagem entre o mundo dos objetos e a bidimensionalidade da representação, deixando bem evidente que a escolarização dos saberes obedecia a uma certa alquimia curricular (POPKEWITZ, 2007).

Todas as prescrições tinham por fim modelar o espírito do aluno para que este se preparasse para receber "o estudo das matemáticas puras". Além do mais, a tão desejada interdisciplinaridade tornava-se possível ao nível dos próprios objetos a observar. Nos trabalhos gráficos em que se pressentisse uma proximidade às ciências naturais, convocarse-ia a presença do respectivo professor no sentido de ministrar as noções correspondentes aos objetos em análise. E os professores, quer de matemática, quer de ciências naturais, em cada ano letivo requisitariam, "como material escolar, os trabalhos gráficos realizados na aula de desenho durante o ano anterior" (PORTUGAL, 1895). Era o desenho a intrometer-se nas salas de aula vizinhas, não pela sua faceta 'artística', mas antes pela componente didáctica ou ilustrativa da sua presença.

Pelo contrário, as ilustrações, ou estampas, na própria aula de desenho, afixadas nas paredes, eram apenas permitidas para a $1^{a}$ e para a $2^{a}$ classes, para os exercícios de ampliação e à escala natural. A gama em que o desenho se desdobrava era extensa: desenho de memória, ditado, desenho de objetos, desenho livre e de invenção, desenho à voz, com tempo marcado e desenho de prova. O método oficial era o stigmográfico. A preparação do dispositivo de visualidade para o seu ensino obedecia a requisitos fundamentais. O professor teria de preparar a sua base de ação, equivalente àquela que seria utilizada individualmente por cada aluno. Desse modo, no quadro preto, gravaria uma grelha de linhas retas horizontais e verticais à distância de 10 centímetros. Para os alunos, quadros à sua medida, de cor castanha, e papel de cor neutra, com ou sem rede stigmográfica. As distâncias dos estigmas, isto é, a distância entre as intersecções das retas variava entre 1 e 5 centímetros.

Revista Digital do LAV - Santa Maria - vol. 14, n. 2, p. 359 - 384 - mai./ago. 2021 ISSN 1983 - 7348 http://dx.doi.org/10.5902/1983734864729 
Numa circularidade infinita, o desenho permitia estabelecer o corpo-instrumento, o corpo-máquina e o corpo-ouvinte, mas também o corpo visível, quer na irregularidade dos gestos, quer na aptidão para realizá-los:

Fazer, com clareza e exactidão, a análise de uma parte do trabalho que tem de ser executado, desenhando-a em seguimento no quadro preto, dando tempo aos discípulos para executarem esta parte, e continuando assim até à conclusão do exercício. Esta variante possui a vantagem de obrigar a classe a um trabalho contínuo e a prestar toda a atenção ao professor. Quando o professor executar o modelo, na presença da classe, traçará as linhas apenas com intensidade bastante para que todos os alunos as possam ver, e exigirá que eles as desenhem o mais ao de leve possível. Depois de completo o esboço, traçará com bastante intensidade as linhas definitivas. Os alunos procederão analogamente, sendo-Ihes permitido o emprego do carvão para o esboço. [...] Na segunda classe o professor fará executar, conforme acima se disse, desenhos de ampliação, na escala por ele designada, e na escala natural. No último caso vigiará que os desenhos não sejam estrezidos, suposto esta fraude não tenha muita probabilidade perante 0 método empregado (PORTUGAL, 1895).

As diretrizes com que fechava a reforma de 1895 continham em si todo o processo simultaneamente individualizante e totalizante da modernidade pedagógica, permitiam o vaivém entre o individual e o colectivo, a produção de imagens de normalidade e anormalidade de acordo com a distância entre as classificações de cada aluno, "a comparação perpétua de cada um com todos que permite ao mesmo tempo medir e sancionar" (FOUCAULT, 2004, p. 155). Mas permitiam também um trabalho mais longo, também ele permanente, sobre si mesmo. O desenho disciplinava, é certo, mas com isso também sublimava as forças e os impulsos do corpo. A energia do aluno era aplicada neste rigor, na obtenção da exactidão, faseada já com momentos de alguma invenção, e este rigor e esta exactidão colavam-se à pele e à alma do aluno. A administração de todos passava pela administração de cada um por si. As disciplinas escolares, com as suas alquimias, ativavam as tecnologias de autogoverno.

\section{Notas Finais}

A breve história aqui ensaiada sobre o começo das artes como uma preocupação na educação das crianças e dos jovens surgiu, em Portugal, à semelhança do que aconteceu noutros países Europeus, a partir de duas origens que poderíamos dizer opostas, mas que, na verdade, se tornaram interdependentes. Se as artes se conceberam como esfera de distinção social, capazes de definir sujeitos cultos e civilizados, isso aconteceu porque foi estabelecido um outro lugar, considerado de abjeção, do qual as artes 
permitiriam uma distanciação. Num plano histórico colonial esse lugar foi o do 'Outro' racializado, dentro das fronteiras imperiais, outros ocuparam esse lugar de 'Outro'. A infância, considerada delinquente, anormal e órfã, foi classificada e remetida para esse território que era necessário conhecer para melhor governar, conter para melhor controlar, educar para regenerar. E, em paralelo, as artes continuaram seguindo o seu caminho de distinção. Foram entendidas, no plano educativo, como possibilidade reguladora de comportamentos, capazes de disciplinar e de preparar o cidadão do futuro como trabalhador, mas também como forma de distinguir, pelas capitais simbólicas e culturais que representavam. Naquele que foi o seu desenvolvimento na educação, as artes, particularmente o desenho, massificam-se. Elas permitiam explorar técnicas de subjetivação dos sujeitos, ativando princípios de autogoverno. Cada vez mais foram faladas a partir das suas potencialidades expressivas e de conhecimento da interioridade dos alunos, permitindo, por isso, no campo educativo, a ação de um poder governamental, e até pastoral, no sentido da condução da conduta do professor e do aluno.

\section{Referências}

ALMEIDA, F. de. Vida Irónica, Jornal d’um Vagabundo. Lisboa: Livraria Clássica Editora, 1892.

ALMEIDA, J. M. E. de. Relatório da administração da Real Casa Pia de Lisboa de 20 de outubro de 1859 a 31 de outubro de 1860, apresentado a Sua Excelência o Ministro do Reino pelo provedor José Maria Eugénio de Almeida. Lisboa: Imprensa Nacional, 1861.

BOURDIEU, P. The State Nobility. Stanford: Stanford University Press, 1996.

BOURDIEU, P. A Distinção. Crítica Social do Julgamento. São Paulo: Zouk, 2007.

BRANCO, C. C. Desenho. In: BRANCO, C. C. Dicionário Universal da Educação e Ensino Útil à Mocidade de Ambos os Sexos, às Mães de Família, aos Professores, aos Directores e Directores de Colégios e aos Alunos que se Preparam para Exame, Redigido com a Colaboração de Escritores Peculiares por E. M. Porto: Livraria Internacional de Ernesto Chardon, 1886.

CHAKRABARTY, D. Provincializing Europe. Postcolonial Thought and Historical Difference. Princeton and Oxford: Princeton University Press, 2008.

COSTA, A. da. A Instrução Nacional. Lisboa: Imprensa Nacional, 1870.

FOUCAULT, M. Vigiar e Punir. História da Violência nas Prisões. Petrópolis: Editora Vozes, 2004.

FOUCAULT, M. Technologies of the Self. In: MARTIN, L. H.; GUTMAN, H.; HUTTON, P. H. (eds.). Technologies Of The Self. A Seminar With Michel Foucault. Massachusetts: The University of Massachusetts Press, 1988, p. 16-49.

Revista Digital do LAV - Santa Maria - vol. 14, n. 2, p. 359 - 384 - mai./ago. 2021 ISSN 1983 - 7348 http://dx.doi.org/10.5902/1983734864729 
FOUCAULT, M. Governmentality. In: BURCHELL, G.; GORDON, C.; MILLER, P. (eds.). The Foucault Effect. Studies in governmentality with two lectures by and an interview with Michel Foucault. Chicago: The University of Chicago Press, 1991, p. 87-104.

FRANKLIN, B. Proposals Relating to the Education of the Youth in Pensilvania. Philadelphia: University of Pennsylvania Press, (s.d.).

GARRETT, A. Da Educação: Cartas dirigidas a uma senhora ilustre encarregada da instituição de uma jovem senhora. Porto: Em Casa da Viúva Moré, 1829.

GAZTAMBIDE-FERNÁNDEZ, R. Why the arts don't do anything: toward a new vision for cultural production in education. Harvard Educational Review, v. 83, n. 1, 211-236, 2013.

GIKANDI, S. Slavery and the Culture of Taste. Princeton: Princeton University Press, 2011.

GOFFMAN, E. Asylums. Essays on the Social Situation of Mental patients and Other Inmates. London: Penguin Books, 1991.

KAMENS, D. H.; CHA, Y.-K. The Formation of New Subjects in Mass Schooling: Nineteenth Century Origins and Twentieth Century Diffusion of Art and Physical Education. In: MEYER, J. W.; KAMENS, D. H.; BENAVOT, A. (eds.), School Knowledge for the Masses. World Models and National Primary Curricular Categories in the Twentieth Century. London: The Falmer Press, 1992, p. 152-164.

MACEDO, J.; SILVA, J.; TRIGOSO, S. Memória da Comissão encarregada de visitar o estabelecimento da Casa Pia. Lisboa: Casa Pia de Lisboa, 1821.

MARGIOCHI, F. S. Relatório da Administração da Real Casa Pia de Lisboa Relativo ao Ano Económico de 1889-1890, Apresentado a Sua Excelência o Ministro do Reino Pelo Provedor Francisco Simões Margiochi. Lisboa: Tipografia Portuense de Pedro Oliveira, 1893.

MARTINS, C. S. "Do you hear with your ears or with your eyes?": The education of the deaf pupils at casa pia de lisboa (c.1820-1950). Paedagogica Historica, v. 45, n. 1-2, 2009.

MARTINS, C. S. The Alchemies of the Arts in Education. Problematizing Some of the Ingredients of the Recipe. In: JORISSEN, B.; KLEPACKI, L.; KLEPACKI, T.; FLASCHE, V.; ENGEL, J.; UNTERBERG, L. (eds.), Spectra of Transformation. Munster and New York: Waxmann, 2018, p. 41-57.

MONIZ, J. Estudos de Ensino Secundário. Lisboa: Imprensa Nacional, 1918.

NESBIT, M. Ready-made Originals: The Duchamp Model. October, v. 37, p. 53-64, 1986.

NESBIT, M. Their Common Sense. United Kingdom: Black Dog Publishing, 2000.

Ó, J. R. do. A Casa Pia (1780-1960) como Laboratório da Modernidade Educativa em Portugal. Lisboa, 2003a.

Ó, J. R. do. O Governo de Si Mesmo: Modernidade Pedagógica e Encenações Disciplinares do Aluno Liceal (Último Quartel do Século XIX - Meados do Século XX). Lisboa: Educa, 2003b.

Revista Digital do LAV - Santa Maria - vol. 14, n. 2, p. 359 - 384 - mai./ago. 2021 ISSN 1983 - 7348 http://dx.doi.org/10.5902/1983734864729 
PESSOA, F. Ode Triunfal. Orpheu, 1, 77-83, 1915.

POPKEWITZ, T. S. The Alchemy of the Mathematics Curriculum: Inscriptions and the Fabrication of the Child. American Educational Research Journal, v. 41, n. 1, p. 3-34, 2004.

POPKEWITZ, T. S. Alchemies and Governing: Or, questions about the questions we ask. Educational Philosophy and Theory, 39, 64-83, 2007.

PORTUGAL. Carta de Lei de 7 de Março de 1761. Criação do Real Colégio dos Nobres. Disponível

em: <http://193.137.22.223/fotos/editor2/RDE/L/S18/1761_1770/1761_03_07_cartadelei.p df>. Acesso em: 18 jun. 2021.

PORTUGAL. Debate Parlamentar de 11 de Janeiro de 1823. Dispõe sobre uma Reforma do Colégio dos Nobres. Disponível em: $<$ https://debates. parlamento.pt/catalogo/mc/cd/listIssuesByYear?ano $=1823>$. Acesso em: 18 jun. 2021.

PORTUGAL. Decreto de 17 de Novembro de 1836. Criação dos Liceus - Reforma de Passos Manuel. Disponível em: <http://193.137.22.223/fotos/editor2/RDE/L/S19/1831_1840/1836_11_17decreto.pdf>. Acesso em: 18 jun. 2021.

PORTUGAL. Decreto de 18 de Novembro de 1836. Criação do Conservatório das Artes e Ofícios em Lisboa. Disponível em: <http://193.137.22.223/fotos/editor2/RDE/L/S19/1831_1840/1836_11_18decreto.pdf>. Acesso em: 18 jun. 2021.

PORTUGAL. Decreto de 5 de Janeiro de 1837. Criação do Conservatório Portuense das Artes O Ofícios. Disponível em: <http://193.137.22.223/fotos/editor2/RDE/L/S19/1831_1840/1837_01_05decreto.pdf>. Acesso em: 18 jun. 2021.

PORTUGAL. Decreto de 20 de Setembro de 1844. Reforma de Costa Cabral. Disponível em:

<http://193.137.22.223/fotos/editor2/RDE/L/S19/1841_1850/1844_09_20decreto.pdf>. Acesso em: 18 jun. 2021.

PORTUGAL. Decreto de 10 de Abril de 1860. Regulamento sobre os Liceus Nacionais. Disponível em: Diário de Lisboa, $1^{a}$ Série, n. 133, de 12 de junho. Acesso em: 18 jun. 2021.

PORTUGAL. Decreto de 5 de Outubro de 1893. Dispõe sobre a necessidade de um museu etnográfico. Disponível em: <https://legislacaoregia.parlamento.pt/V/1/78/125/p1026>. Acesso em: 18 jun. 2021.

PORTUGAL. Decreto de 14 de Agosto de 1895. Regulamento da reforma do Ensino Liceal. Disponível em: <https://legislacaoregia.parlamento.pt/V/1/81/123/p689>. Acesso em: 18 jun. 2021.

PORTUGAL. Decreto de 5 de Dezembro de 1918. Dispõe sobre a organização do ensino industrial e comercial. Disponível em: <https://dre.pt/application/conteudo/183179>. Acesso em: 18 jun. 2021.

RAPOSO, J. A. S. Relatório das Aulas da Real Casa Pia de Lisboa Apresentado à

Revista Digital do LAV - Santa Maria - vol. 14, n. 2, p. 359 - 384 - mai./ago. 2021 ISSN 1983 - 7348 http://dx.doi.org/10.5902/1983734864729 
Exma Administração Pelo Provisor dos Estudos José António Simões Raposo. Lisboa: Tipografia de M. da Costa, 1869.

RIBEIRO, J. S. História dos Estabelecimentos Científicos, Literários e Artísticos de Portugal nos Sucessivos Reinados da Monarquia. Tomo III. Lisboa: Tipografia da Academia Real das Ciências, 1873.

RODRIGUES, F. de A. Discurso Pronunciado por Francisco de Assis Rodrigues na Sessão Pública Trienal e Distribuição de Prémios da Academia de Belas Artes de Lisboa na Presença de Suas Magestades Fidelíssimas em 29 de março de 1862. Lisboa: Tipografia de José Baptista Morando, 1862.

ROSE, N. Governing the Soul: The Shape of the Private Self. London: Routledge, 1990.

STEVENS, E. W. The Grammar of the Machine. Technical Literacy and Early Industrial Expansion in the United States. New Haven and London: Yale University Press, 1995.

VASCONCELOS, J. de. A Exposição das Escolas de Desenho Industrial. Porto: Tipografia do Comércio do Porto, 1891.

i Professora na Faculdade de Belas Artes da Universidade do Porto e Investigadora Integrada do i2ADS - Instituto de Investigação em Arte, Design e Sociedade. Diretora do Doutoramento em Educação Artística da Universidade do Porto.

Como citar esse artigo:

MARTINS, Catarina Silva. O governo e o autogoverno do aluno no ensino do desenho em Portugal (séculos 18 e 19). Revista Digital do LAV, Santa Maria: UFSM, v. 14, n. 2, p. 359-384, mai./ago. 2021. 